\title{
THE USE OF PHOTON DENSITOMETRY TO EVALUATE BONE MINERAL IN A GROUP OF PATIENTS WITH SPINAL CORD INJURY
}

\author{
By Harry J. Griffiths, M.D. \\ Harvard Medical School and Peter Bent Brigham Hospital, Boston, \\ Massachusetts, U.S.A. \\ and \\ Robert E. Zimmerman, M.S.E.E. \\ Department of Nuclear Medicine, Peter Bent Brigham Hospital, Boston, \\ Massachusetts, U.S.A.
}

\section{INTRODUCTION}

For 50 years, the measurement of 'bone density' has depended on radiographic means. However, even the most exacting radiographic method is incapable of showing changes in bone composition with any precision. It is a well-known fact that it is impossible to demonstrate osteoporosis radiologically until 40 per cent. of bone mineral has been lost (Ardran, I95I). Even extremely accurate techniques such as those used by Meema et al. (I964) and Doyle (I96I) are only capable of measuring 20 per cent. changes in bone density. They measure the cortical width of various peripheral bones and attempt to correlate the gross changes this shows with the discrete alterations in bone mineral mass that actually occur.

Some ro years ago the technique of scanning using an isotope point source was introduced by Cameron and Sorenson (1963) and over the intervening decade this method has been further improved (Sorenson and Cameron, 1967). They claim a 2 per cent. reproducibility on bones in vitro and a 5 per cent. reproducibility on patients. This technique has been used to evaluate patients suffering from a variety of conditions such as idiopathic osteoporosis, renal failure and prolonged immobilisation.

\section{MATERIAL AND METHODS}

In the initial study, bone mineral determinations were performed using the Cameron technique. Our unit, manufactured by the Packard Instrument Company, utilises a $400 \mathrm{mCi}^{125} \mathrm{I}$ point source. Scanning speed is held constant at $\mathrm{I} \cdot 25 \mathrm{~cm}$./min. and accumulated counts are read out on the printer every millimetre. Scanning time for a typical arm is about seven minutes and a minimum of two scans are performed on each subject (fig. I). In patients without spinal cord injury, water is used as a tissue equivalent substance in a specially designed armbox. However, in many of the spinal cord injury patients, this proved impracticable and 'Super Stuff' was used in another armbox. Cortical bone was scanned at the junction of the proximal two-thirds with the distal one-third of the radius and ulna. In a given individual results show a $3 \frac{1}{2}$ per cent. reproducibility and the system is capable of demonstrating 2 per cent. change in bone mineral (fig. 2).

One hundred patients with spinal cord injury were studied and these were matched with 100 normals. There were 59 quadriplegic and 4I paraplegic patients 


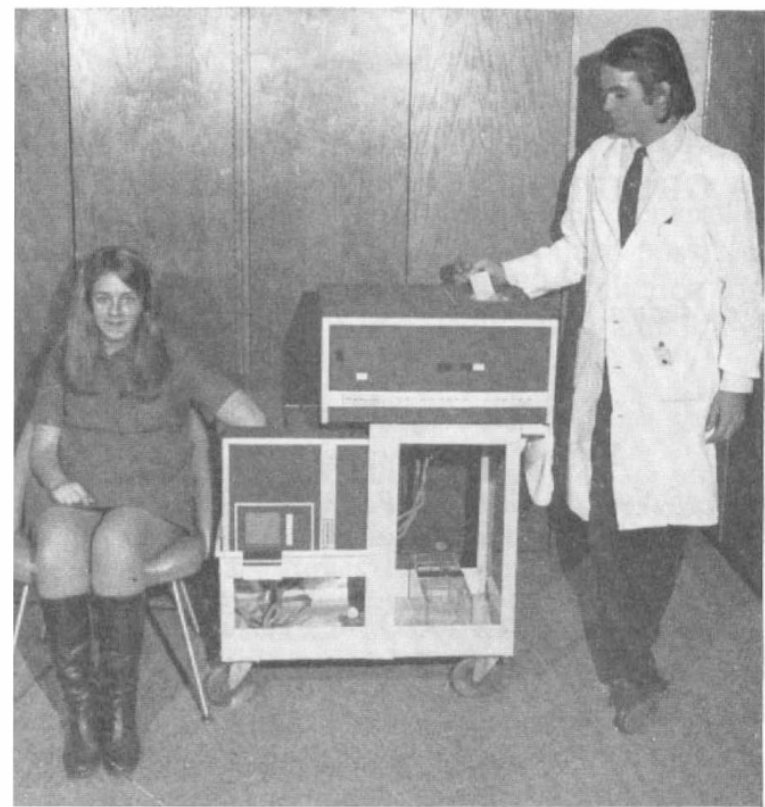

FIG. I

Packard Osteodensitometer. The specially designed armbox for normal patients is situated in the scanner on the lower level. The digital readout comes from the top of the upper part of the machine.

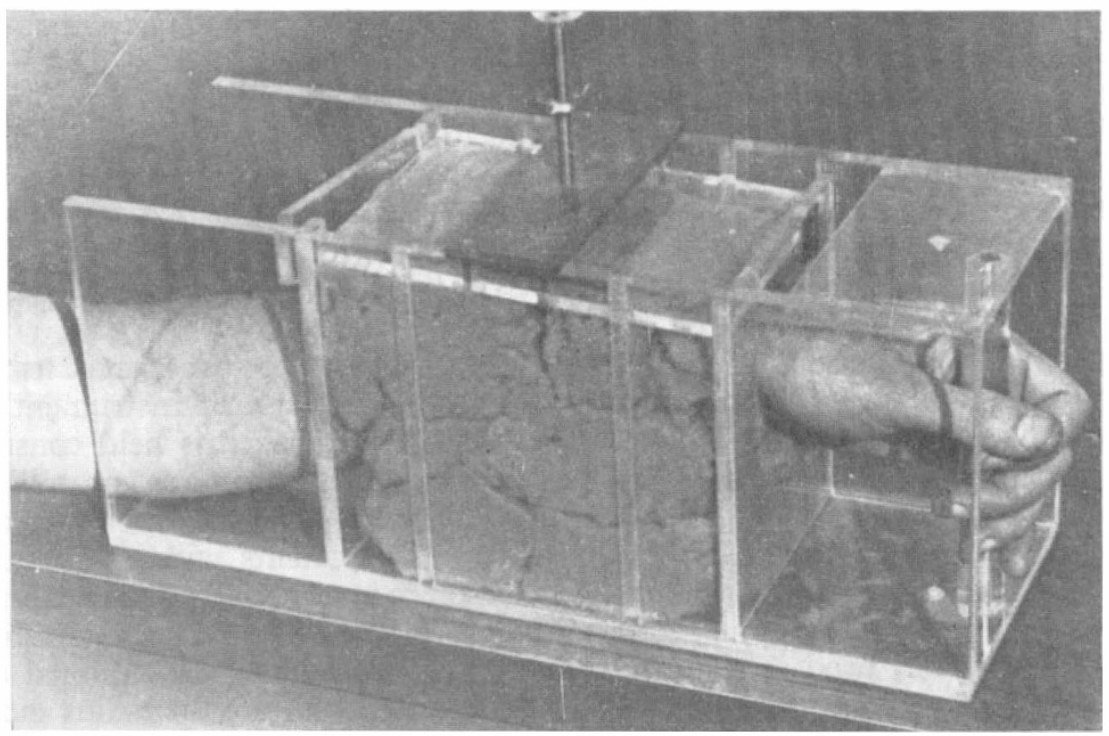

FIG. 2

Armbox for spinal cord injury patients. The arm is placed in the box and 'Super Stuff' is packed around the forearm. A guillotine-like arrangement compresses the tissue equivalent substance. 
and full clinical data is available on all of them. Their age range was from in to 79 years with peaks at 20 to 25 years and 40 to 55 years. The level of injury ranged from $\mathrm{CI}_{\text {in }}$ one patient to $\mathrm{L}_{4}$ in five patients with a peak at $\mathrm{C}_{5}$. This was associated with the high incidence of whip lash injuries from automobile accidents, as well as those injured from diving into shallow water.

The date of injury ranged from before I945 (seven patients injured during war) to 1970 ( 20 patients of whom I3 were injured in combat in Vietnam). All the spinal cord injury patients had bone scans and their clavicular index was measured from chest X-rays. Ninety per cent. had their metacarpal index measured from $\mathrm{X}$-rays of the hands.

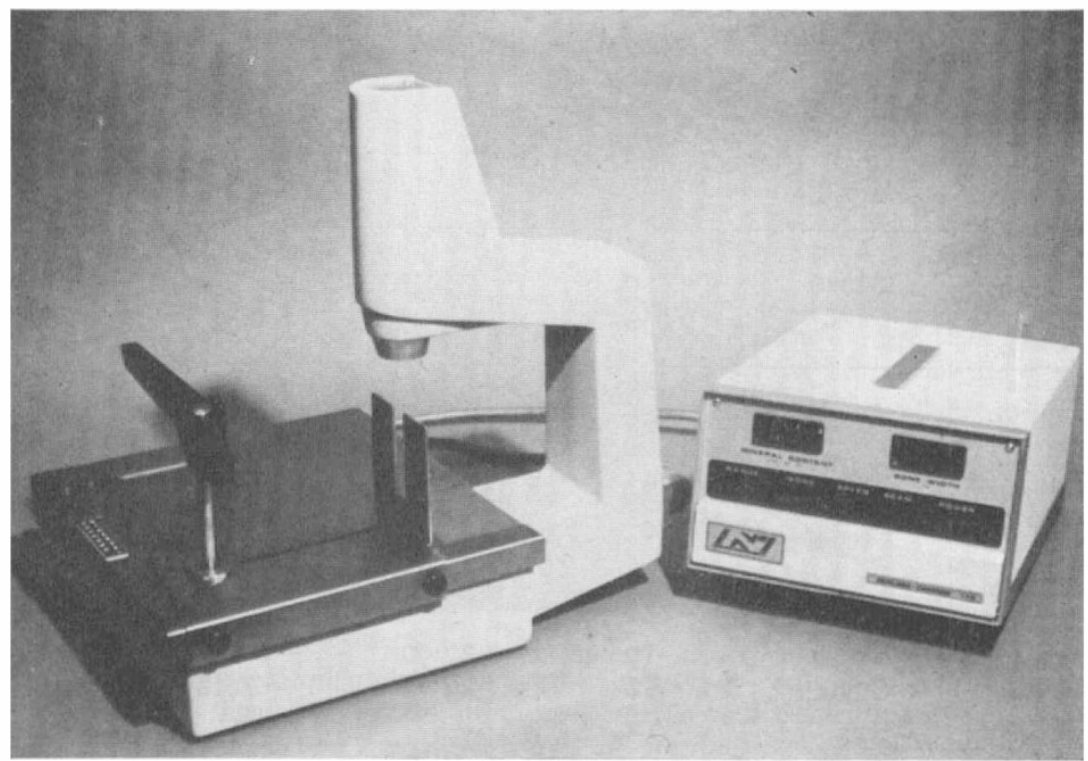

FIG. 3

Norland-Cameron Bone Mineral Analyser. The scanner module is on the left with the computer module on the right. The arm is placed across the scanner surrounded by water in a specially designed bag.

More recently, a commercially available osteodensitometer produced by Norland was used.* This works on the same principle as the Packard but produces an instant read out (fig. 3). Thirty-six patients were rescanned and of these, 22 were quadriplegic and the remaining I4 were paraplegic. Each patient was scanned across the lower arm at the wrist for trabecular bone and one-third of the way up the radius for cortical bone.

\section{RESULTS}

The bone mineral measurements of cortical bone at the lower radius and ulna showed no significant difference between normal patients and those patients with spinal cord injury (Table I).

* Marketed in Europe by Old Delft. 
The measurement of metacarpal index and clavicular index were also within normal limits. In relating age to bone mineral units in the group of spinal cord injury patients, there was no significant difference between those injured and those not. Also no statistical correlation could be demonstrated between bone mineral mass and the date or level of the injury.

Finally, 90 per cent. of the patients with spinal cord injuries had hand X-rays, and immobilisation, or so-called disuse osteoporosis, was demonstrable in over half of the patients, 58 of whom were quadriplegic and 22 paraplegic. Disuse osteoporosis is characterised by patchy loss of bone trabeculae most marked adjacent to the joints, particularly around the radiocarapal joint. The corticies of the lower

TABLE I

Cortical Bone

Mean Readings of Bone Mineral Units

(B.M.U.) in the Two Age Groups*

\begin{tabular}{|c|c|c|c|c|c|}
\hline & $\begin{array}{c}\text { Mean } \\
\text { age }\end{array}$ & $\begin{array}{c}\text { No. } \\
\text { patients }\end{array}$ & $\begin{array}{c}\text { Mean } \\
\text { B.M.U. }\end{array}$ & Slope & $\begin{array}{l}\text { Standard } \\
\text { error }\end{array}$ \\
\hline $\begin{array}{l}\text { Age range } \\
20-55\end{array}$ & & & & & \\
\hline Normals & $35 \cdot 36$ & 95 & $23 \cdot 33$ & 0.0293 & 0.0339 \\
\hline Injured & 37.52 & 71 & $23 \cdot 18$ & -0.03652 & 0.0529 \\
\hline $\begin{array}{c}\text { Age range } \\
56 \text { and above }\end{array}$ & & & & & \\
\hline Normals & 63.00 & I9 & $22 \cdot 90$ & -0.1390 & 0.156 \\
\hline Injured & $6 \mathrm{I} \cdot 8 \mathrm{I}$ & 16 & $23 \cdot 21$ & -0.1162 & $0.22 \mathrm{I}$ \\
\hline
\end{tabular}

* Standard errors are noted to be reasonably small.

radius and ulna, as well as the metacarpals appear to be intact. This tends to confirm our findings with the photon scanner (fig. 4).

On rescanning these patients with the Norland machine, we failed to produce such accurate and reproducible results as with the original technique, and thus the data is difficult to analyse, However. this machine was easier to use on patients with spinal cord injury and has the advantages of being simple to set up at the bedside and more aesthetically pleasing to the patient who can see what is happening.

The preliminary results for this study are shown in Table II. There is less bone mineral in the trabecular bone of the radius than in the cortical bone and if the relative widths of the bone at the two levels of scan are taken into account this discrepancy would become even more marked.

If the patients are grouped according to the degree of this loss of trabecular bone, there are three distinct groups. One small group has virtually the same readings as cortical bone. Nearly half the patients showed marked loss of trabecular bone. Seven of these patients were paraplegic and this represents 50 per 


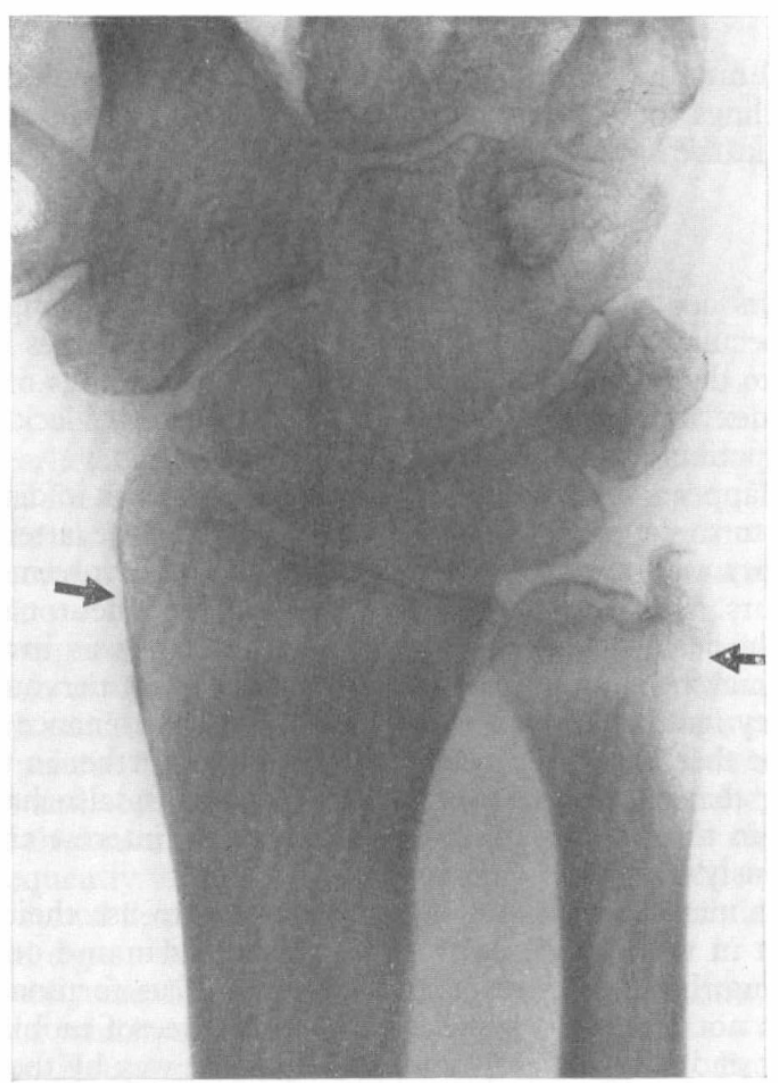

FIG. 4

Male paraplegic patient aged 53 who received a partial $\mathrm{C}_{5}$ injury 22 years previously. His trabecular bone measurement was the lowest of the group (I5.6 B.M.U.).

TABLE II

Trabecular Bone

Mean Bone Mineral Readings

\begin{tabular}{|c|c|c|c|c|c|}
\hline & \multicolumn{3}{|c|}{ No. of patients } & \multirow{2}{*}{$\begin{array}{c}\text { Mean } \\
\text { B.M.U. }\end{array}$} & \multirow{2}{*}{$\begin{array}{c}\text { Standard } \\
\text { deviation }\end{array}$} \\
\hline & Total & Quads & Paras & & \\
\hline Total & $34^{*}$ & $2 I$ & I3 & $22 \cdot 04$ & $\pm 4 \cdot 57$ \\
\hline Group (I) & 3 & 3 & - & $26 \cdot 36$ & $\pm 5 \cdot 84$ \\
\hline Group (2) & I5 & 9 & 6 & $23 \cdot 30$ & \pm 3.93 \\
\hline Group (3) & I6 & 9 & 7 & $20 \cdot 10$ & $\pm 3 \cdot 77$ \\
\hline
\end{tabular}

* 2 patients have insufficient data to be analysed statistically.

Note: For this group of 34 patients, the mean B.M.U. of cortical bone was $24 \cdot 00 \pm 4 \cdot I 0$. 
cent. of the total number of paraplegics in this group. This tends to confirm the radiographic findings that 54 per cent. of all paraplegic patients show some loss of trabecular bone in the lower arm.

\section{DISCUSSION}

These results are of considerable interest, since it has long been held that cortical and trabecular bone respond similarly, although changes in the trabecular bone are easier to demonstrate radiographically. Our findings of a normal range of metacarpal index and clavicular index tend to confirm this lack of change in the cortical bone in patients with spinal cord injury.

Thus, there appears to be a different mechanism at work in disuse osteoporosis when compared to so-called idiopathic osteoporosis. In the latter condition there is in all probability a hormonal mechanism at work and involvement of the entire bone matrix occurs. In spinal cord injury there may be a neuronal element which could mediate the loss of bone. This type of osteoporosis involving only the trabecular bone may be confined to patients with a central nervous system injury. Undoubtedly they have loss of trabecular bone and maintenance of cortical bone and it is our hope that we will be able to elucidate this further in the future.

The finding that 54 per cent. of paraplegic patients also have some loss of trabecular bone in the upper extremity is of extreme interest and has not been described previously.

The patients mentioned in this article were able to use their arms to propel themselves about in wheelchairs and to lift themselves in and out of bed and so should, if anything, have stronger arms than those of us fortunate enough to be normal. It does not appear to be related to the degree of mobilisation for each particular patient and it is probably controlled in some way by the central nervous system since it is not apparently mediated by either usage or generalised hormonal control.

\section{SUMMARY}

Using two systems which depend on photon absorption techniques for measuring bone mineral, it has been demonstrated that in a group of patients with spinal cord injury there is loss of trabecular bone with preservation of cortical bone. The reason for this is as yet unexplained but may in part be related to the primary injury being that of the central nervous system.

\section{REFERENCES}

ARdran, G. M. (I95I). Brit. F. Rad. 24, IO7-IO9.

CAMERON, J. R. \& SORENSON, J. (1963). Science, 142, 230.

DoYLe, F. H. (I96I). Brit. F. Rad. 34, 698..

MeEma, H. E., Harris, C. K. \& Porrett, R. E. (I964). Radiology, 82, 986.

SORENSON, J. A. \& CAMERON, J. R. (I967). F. Bone foint Surg. 49A, 48I. 